\title{
Impact of Clinical Pharmacist Mediated Patient Counseling on Health Related Quality of Life in Rheumatoid Arthritis Patients in Healthcare Resource Limited Settings of India
}

\author{
Mohanraj Rathinavelu Mudhaliar,,2, Samhitha Reddy Yiragamreddy ${ }^{1,2}$, Ishrar Shaik Mohammad \\ Ghouse ${ }^{1,2}$, Javeed Patta ${ }^{3^{*}}$, Ushanandhini Tabula ${ }^{3}$, Praveen Kumar ${ }^{4}$ \\ ${ }^{1}$ Division of Pharmacy Practice, Raghavendra Institute of Pharmaceutical Education \& Research RIPER, Anantapuramu, Andhra \\ Pradesh, INDIA. \\ ${ }^{2}$ Drug Information Pharmacist, Poison and Drug Information Centre, Department of Pharmacy Practice, RDT Hospital, Bathalapalli, \\ Anantapuramu, Andhra Pradesh, INDIA. \\ ${ }^{3}$ Resident Intern, VI Year Pharm D, Division of Pharmacy Practice, Raghavendra Institute of Pharmaceutical Education \& Research \\ RIPER, Anantapuramu, Andhra Pradesh, INDIA. \\ ${ }^{4}$ Department of Orthopedics, RDT Hospital, Bathalapalli, Anantapuramu, Andhra Pradesh, INDIA.
}

\begin{abstract}
Background: Rheumatoid arthritis is defined as a chronic, progressive, auto immune mediated systemic inflammatory disease that primarily affects synovial joints. The management of rheumatoid arthritis according to the American College of Rheumatology (ACR) aims in relieving pain and discomfort and ameliorate symptoms; arrest or limit disease progression and, if possible, reverse pathological changes; maintain mobility and function, and promote the best possible quality of life, were pharmacist role is considered significant. Materials and methods: The current prospective interventional study (quasi experimental design) was conducted in a secondary care hospital for a period of six months to evaluate the impact of clinical pharmacist mediated patient counseling on health related quality of life in rheumatoid arthritis. The study involved collection of data by administration of a questionnaires SF-36 health survey during the first visit through direct patient interview. After which counseling was provided regarding disease, drug and lifestyle modifications by using a patient information leaflet. At the second visit the same questionnaire was administered and the responses were documented, finally the comparative score was calculated and the improvement in quality of life was calculated. Results: Our study observed that there is a significant difference in the quality of life in rheumatoid arthritis in all the domains both physically and mentally after providing the patient education through the patient information leaflet and the mean quality of life score for baseline and follow up visits $28.98 \pm 16.35,41.17 \pm 16.15,37.5 \pm 16.23$ respectively. Conclusion: Pharmacist based patient education and counseling may have greater positive impact on the quality of life in rheumatoid arthritis patients.
\end{abstract}

Key words: Prospective interventional study, Pharmacists, Patient counseling, Quality of life, Rheumatoid arthritis.

\section{INTRODUCTION}

Rheumatoid Arthritis (RA) is a chronic inflammatory disease with unknown etiology that affects commonly diarthrodial joints but often with periarticular and systemic involvement. Rheumatoid arthritis was coined in 1858 as a label for cases reported by a French medical student in $1800 .{ }^{1,2}$ The prevalence of rheumatoid arthritis for every 1, 00,000 population is 1136 the prevalence rate is high in age group of 60-74 yrs where as low in 15-29 years age group. Females are affected 2 times more
DOI: 10.5530/ijopp.9.4.6

Address for correspondence:

Mr. Javeed Patta.

Pharm. D, Resident Intern, Doctor of PharmacyDepartment of Pharmacy Practice

Raghavendra Institute of Pharmaceutical Education and Research RIPER

Anantapuramu, Andhra Pradesh, INDIA.

Phone no: +918121934940 E-mail: moley4u@rediffmail. com

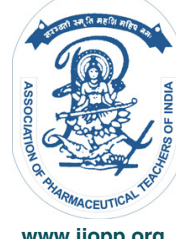

www.ijopp.org 
than a male and the prevalence of the disease increases with age and gender. ${ }^{3}$ The etiology of RA is unknown but most possible involving factors are genetic predisposition, ${ }^{1,3}$ infectious origins, ${ }^{1,4}$ psychosocial aspects, ${ }^{5-7}$ Some of the studies suggest that depression is more commonly seen in females in severe cases antidepressant treatment and cognitive behavioral therapy can improve the condition. The health care professionals should evaluate not only the physical limitations but also the mental health and perceptions of patients towards the disease which may increase the quality of life in rheumatoid arthritis. ${ }^{4,8}$ The pharmacotherapy of rheumatoid arthritis involves four categories of medications NonSteroidal Anti-Inflammatory Drugs (NSAID's), Disease Modifying Anti-Rheumatoid Drugs (DMARD's), biological therapies and glucocorticoid.

The world health organization defines quality of life as "an individual's perception of their position in life in the context of the culture and value systems in which they live and in relation to their goals, expectations, standard and concerns". ${ }^{9,10}$ The state of wellbeing is essential to the concept of quality of life. It refers to the patient's own evaluation of disease. The impact of the illness on various aspects of life depends completely on patient's life style, occupation and socioeconomic state..$^{9-11}$

Daily pain, stiffness, fatigue and physical disability are commonly found in rheumatoid arthritis and its effects on all the aspects of quality of life. ${ }^{12}$ The socioeconomic status and disability to do work with pain which shows a negative effect on the individuals quality of life and some of the research studies on rheumatoid arthritis suggests that due disease disability and some external factors such as education, gender, social life influences the health related quality of life in rheumatoid arthritis. ${ }^{8,13}$

Most patients will have joint destruction, functional impairments and increased mortality having a great impact on patients' Health-Related Quality Of Life (HRQOL) in rheumatoid arthritis. Furthermore, patients have often adapted to their life with RA and have cognitively integrated the illness into their lives by redefining their internal standards of what comprises health, changing their values and priorities and/or redefining the concept of quality of life. ${ }^{12,14}$

Health related quality of life instruments are available to measure the quality of life in rheumatoid arthritis. The instruments used to measure the quality of life are Health assessment questionnaire-disability index Short Form-36. ${ }^{15}$ Health Assessment Questionnaires (HAQ) remains the gold standard for measuring functional status in rheumatoid arthritis. although physical function is the only one of several domains determining health related quality of life increases its importance in rheumatoid arthritis. ${ }^{16}$

The Shortform-36 health survey a general health status questionnaire designed in the USA. The SF 36 includes 8 scales that assess pain, physical functioning, general health, fatigue/vitality, mental health, social functioning, and role limitations due to either physical (or) emotional problems. Two summary scores, the SF-36 therefore assess a broader range of health concerns than rheumatoid arthritis specific measures and because it is a generic measure comparison are possible across diseases. In common with the HAQ, it has the advantage of describing the impact of the disease in terms of patient-centered outcomes rather than the biological or disease-centered outcomes perceived by clinicians. but HAQ does not takes into account of emotional and psychological problems experienced by the patient, and which may affect patients' perceptions of their disease severity It differs from the HAQ because it has questions designed to assess eight areas of health, ranging from those related to limitations in physical activities caused by disease to general perceptions of vitality and health. Hence the use of SF-36 with HAQ is beneficial to measure the quality of life in rheumatoid arthritis. ${ }^{17,18}$ The investigations useful for monitoring the response of the treatment are Erythrocyte Sedimentation Rate (ESR) and C-Reactive Protein(CRP) which are inflammatory markers and rheumatoid factor which is an antibody present in the rheumatoid arthritis. ${ }^{16,17}$

The pharmacist plays an important role in rheumatoid arthritis including improving patient adherence, educating and counseling the patients about the disease and drugs. As per pharmaceutical care concept pharmacists play an imperative role in establishing patient relationships, obtaining medication history information, preventing, and identifying and resolving medication related problems.

\section{MATERIALS AND METHODS}

The prospective interventional study (Quasi experimental design) of six months duration was carried out in department of orthopedics of a secondary care referral hospital in India. The study was approved by the hospital authority by obtaining a proper consent on submission of the profoma of the entire study. The ambulatory patients of either sex diagnosed with rheumatoid arthritis of age above 18 years were included in the study. Inpatients, pediatric patients and pregnant women were excluded from the study.

Study Procedure: The study was performed initially by obtaining a proper informed consent from hospital authority and Institutional Review Board (IRB) of the 
institution to which the research scholar belongs. The study was carried in ambulatory patients visiting orthopedic department who acknowledged their participation after getting informed regarding the significance of the study obtained through written informed consent. The sample sizes of 64 patients who meet the inclusion criteria are recruited. The demographic details and baseline characteristics like age, gender, pain history, were obtained and documented. The questionnaires used in this study are health assessment questionnaire for rheumatoid arthritis and SF-36 health survey which consists of questions related to rigidity, pain intensity, and physical exercise, sensorial function, past, present and future perceptions of their position in life and health outcome measures such as ESR (Erythrocyte Sedimentation Rate), rheumatoid factor (RF), CRP (C-reactive protein) were taken. At the first visit through direct patient interview, all the data's pertaining to questionnaires of Quality Of Life (QOL) was obtained; suitable score are given after collecting these data from the patient. Counseling is provided regarding disease, drug and lifestyle modifications by using a patient information leaflet prepared in the regional language. During the second visit once again the patient were administered with questionnaire, responses are obtained and documented and suitable score is given. The results of first and second visit are compared and outcomes are measured. The baseline and follow up were included to analyze the data statistically; paired " $\mathrm{t}$ " test was selected to analyze the significant difference between baseline and follow-up. Graph pad in stat version 3.0 was used to carry out statistical test.

\section{RESULTS}

The present study involved 64 patients, diagnosed with rheumatoid arthritis. Demographic details of the participants involved in the study was categorized based on gender distribution, age distribution, body mass index (BMI), marital status, social history, family history and concomitant diseases the results of which were thoroughly analyzed and reported in Table 1 (Demographic details of the study participants). Quality of life Short form -36 health survey, assessed by the response to the physical functions, role physical, body pain, general health, vitality, role emotional, social functions, mental health results of which are reported in Table 2 (Comparative responses to Quality of life Short form -36 health survey in baseline with first follow-up and second follow-up). The health outcome in terms of ESR/RF/CRP as parameters in comparison of baseline with first follow-up and second follow-up is analyzed and reported in Table 3 (Comparative responses to Quality of life Short form -36 health survey in baseline with first follow-up and second follow-up in terms of health outcome). The quality of life (QOL) in patients diagnosed with rheumatoid arthritis was assessed with help of responses to HAQ questionnaire, comparison of baseline with first follow-up and second follow-up. The results of which are reported in Table 4 (Comparison of quality of life at baseline, first follow up and second follow up).

\section{DISCUSSION}

Several studies assessed the impact of rheumatoid arthritis on quality of life which has been conducted in recent years. Most of them are cross sectional and case control studies which are conducted among rheumatoid arthritis patients to know the extent of health related quality of

Table 1: Demographic details of the study participants

\begin{tabular}{cccc} 
S.NO Patient characteristics & $\begin{array}{c}\text { No of } \\
\text { subjects }\end{array}$ Percentage \\
\hline
\end{tabular}

1. Gender Distribution

$\begin{array}{ccc}\text { Male } & 24 & 37.5 \\ \text { Female } & 40 & 62.5\end{array}$

2. Age Distribution

$\begin{array}{ccc}20-30 & 05 & 7.812 \\ 30-40 & 10 & 15.62 \\ 40-50 & 30 & 46.87 \\ 50-60 & 14 & 21.87 \\ 60-70 & 05 & 7.81\end{array}$

3. BMI (Body Mass Index)

$\begin{array}{ccc}\text { Underweight } & 05 & 7.81 \\ \text { Normal weight } & 25 & 39.06 \\ \text { Overweight } & 20 & 31.25 \\ \text { Obese } & 14 & 21.87\end{array}$

4. Marital status

$\begin{array}{lll}\text { Married } & 50 & 78.12\end{array}$

$\begin{array}{lll}\text { Unmarried } & 05 & 7.81\end{array}$

$\begin{array}{lll}\text { Divorced } & 02 & 3.12\end{array}$

$\begin{array}{lll}\text { Widow } & 07 & 10.93\end{array}$

5. Smoking status/Social history

Smoker

$30 \quad 46.87$

$\begin{array}{lll}\text { Non smoker } & 25 & 39.06\end{array}$

$\begin{array}{lll}\text { Past smoker } & 05 & 7.81\end{array}$

$\begin{array}{lll}\text { Chain smoker } & 04 & 6.25\end{array}$

6. Family history

$\begin{array}{lll}\text { Present } & 40 & 6.25\end{array}$

Absent $\quad 20 \quad 31.25$

7. Concomitant disease

$\begin{array}{ccc}\text { Diabetes mellitus } & 14 & 6.25 \\ \text { Hypertension } & 12 & 18.75 \\ \begin{array}{c}\text { Diabetes mellitus and } \\ \text { hypertension }\end{array} & 10 & 15.62 \\ \text { Thyroid disorders } & 02 & 31.25\end{array}$


Table 2: Comparative responses to Quality of life Short form -36 health survey in baseline with first follow-up and second follow-up

Comparison of responses to Physical function

\begin{tabular}{|c|c|c|c|}
\hline $\begin{array}{c}\text { Mean base line score } \\
\quad \pm S D\end{array}$ & Mean $1^{\text {st }}$ follow up \pm SD & $\begin{array}{c}\text { Mean } 2^{\text {st }} \text { follow up } \pm \\
\text { SD }\end{array}$ & $P$ - value \\
\hline $28.98 \pm 16.35$ & $37.50 \pm 16.23$ & $41.17 \pm 16.15$ & $<0.0001$ \\
\hline \multicolumn{4}{|c|}{ Comparison of responses to Role Physical } \\
\hline $\begin{array}{l}\text { Mean base line score } \\
\pm \mathrm{SD}\end{array}$ & Mean $1^{\text {st }}$ follow up $\pm S D$ & $\begin{array}{c}\text { Mean } 2^{\text {st }} \text { follow up } \pm \\
S D\end{array}$ & $P$ - value \\
\hline $25.09 \pm 14.91$ & $34.23 \pm 17.52$ & $43.76 \pm 20.43$ & $<0.0001$ \\
\hline \multicolumn{4}{|c|}{ Comparison of responses to Body Pains } \\
\hline $\begin{array}{c}\text { Mean base line score } \\
\pm \text { SD }\end{array}$ & Mean $1^{\text {st }}$ follow up $\pm S D$ & $\begin{array}{c}\text { Mean } 2^{\text {st }} \text { follow up } \pm \\
\text { SD }\end{array}$ & $P$ - value \\
\hline $47.35 \pm 12.80$ & $36.68 \pm 10.90$ & $31.70 \pm 9.835$ & $<0.0001$ \\
\hline \multicolumn{4}{|c|}{ Comparison of responses to General health } \\
\hline $\begin{array}{c}\text { Mean base line score } \\
\pm \mathrm{SD}\end{array}$ & Mean $1^{\text {st }}$ follow up $\pm S D$ & $\begin{array}{c}\text { Mean } 2^{\text {st }} \text { follow up } \pm \\
\text { SD }\end{array}$ & $P$ - value \\
\hline $28.37 \pm 12.86$ & $37.28 \pm 12.65$ & $41.85 \pm 12.59$ & $<0.0001$ \\
\hline \multicolumn{4}{|c|}{ Comparison of responses to Vitality } \\
\hline $\begin{array}{c}\text { Mean base line score } \\
\pm \text { SD }\end{array}$ & Mean $1^{\text {st }}$ follow up $\pm S D$ & $\begin{array}{c}\text { Mean } 2^{\text {st }} \text { follow up } \pm \\
\text { SD }\end{array}$ & $P$ - value \\
\hline $40.78 \pm 11.49$ & $49.48 \pm 10.83$ & $54.46 \pm 11.02$ & $<0.0001$ \\
\hline \multicolumn{4}{|c|}{ Comparison of responses to Role emotional } \\
\hline $\begin{array}{c}\text { Mean base line score } \\
\pm \text { SD }\end{array}$ & Mean $1^{\text {st }}$ follow up $\pm S D$ & $\begin{array}{c}\text { Mean } 2^{\text {st }} \text { follow up } \pm \\
\text { SD }\end{array}$ & $P$ - value \\
\hline $33.38 \pm 19.20$ & $45.632 \pm 20.333$ & $58.18 \pm 20.12$ & $<0.0001$ \\
\hline \multicolumn{4}{|c|}{ Comparison of responses to Social function } \\
\hline $\begin{array}{c}\text { Mean base line score } \\
\pm S D\end{array}$ & Mean $1^{\text {st }}$ follow up $\pm S D$ & $\begin{array}{c}\text { Mean } 2^{\text {st }} \text { follow up } \pm \\
\text { SD }\end{array}$ & $P$ - value \\
\hline $35.12 \pm 16.2$ & $48.42 \pm 15.02$ & $58.17 \pm 14.3$ & $<0.0001$ \\
\hline \multicolumn{4}{|c|}{ Comparison of responses to Mental Health } \\
\hline $\begin{array}{c}\text { Mean base line score } \\
\pm S D\end{array}$ & Mean $1^{\text {st }}$ follow up $\pm S D$ & $\begin{array}{c}\text { Mean } 2^{\text {st }} \text { follow up } \pm \\
\text { SD }\end{array}$ & $P$ - value \\
\hline $42.57 \pm 12.07$ & $53.82 \pm 10.792$ & $62.141 \pm 13.412$ & $<0.0001$ \\
\hline
\end{tabular}

Table 3: Comparative responses to Quality of life Short form -36 health survey in baseline with first follow-up and second follow-up in terms of health outcome

Comparison of responses to Erythrocyte sedimentation rate (ESR)

\begin{tabular}{|c|c|c|c|}
\hline $\begin{array}{c}\text { Mean base line score } \\
\pm S D\end{array}$ & Mean 1st follow up \pm SD & Mean $2^{\text {st }}$ follow up $\pm S D$ & $P$ - value \\
\hline $72.04 \pm 41.53$ & $59.51 \pm 36.18$ & $45.15 \pm 28.15$ & $<0.0001$ \\
\hline \multicolumn{4}{|c|}{ Comparison of responses to Rheumatoid factor (RF) } \\
\hline $\begin{array}{c}\text { Mean base line score } \\
\pm \text { SD }\end{array}$ & Mean 1st follow up \pm SD & Mean $2^{\text {st }}$ follow up $\pm S D$ & $P$ - value \\
\hline $31.97 \pm 37.013$ & $25.96 \pm 30.54$ & $10.27 \pm 5.24$ & $<0.0001$ \\
\hline \multicolumn{4}{|c|}{ Comparison of responses to $C$ reactive protein (CRP) } \\
\hline $\begin{array}{c}\text { Mean base line score } \\
\quad \pm S D\end{array}$ & Mean 1st follow up \pm SD & Mean $2^{\text {st }}$ follow up $\pm S D$ & $P$ - value \\
\hline $1.739 \pm 2.137$ & $1.259 \pm 1.056$ & $0.685 \pm 0.326$ & $<0.0001$ \\
\hline
\end{tabular}

life affected due to disease. There are few studies to assess the quality of life in patients after providing the patient counseling regarding disease, drug therapy and life style modifications which shows significant improvement in medication adherence and quality of life. ${ }^{19}$

In the present study, baseline characteristics shows that females are twice more effected than males to develop 


\begin{tabular}{|c|c|c|c|}
\hline \multirow{2}{*}{ Activity of daily living } & \multicolumn{3}{|c|}{ Mean scores } \\
\hline & Baseline & $1^{\text {st }}$ follow up & $2^{\text {nd }}$ follow up \\
\hline $\begin{array}{l}\text { Dress yourself, plus } \\
\text { doing buttons }\end{array}$ & $1.43 \pm 1.08$ & $0.67 \pm 0.81$ & $0.64 \pm 0.78$ \\
\hline Get in and out of bed & $2.00 \pm 1.06$ & $1.09 \pm 0.97$ & $1.06 \pm 0.95$ \\
\hline $\begin{array}{l}\text { Lift a full cup/glass to } \\
\text { your mouth }\end{array}$ & $1.50 \pm 1.20$ & $1.03 \pm 1.02$ & $0.84 \pm 0.91$ \\
\hline Climb up five steps & $2.26 \pm 0.87$ & $1.81 \pm 0.81$ & $1.45 \pm 0.81$ \\
\hline Get on and off the toilet & $1.29 \pm 0.95$ & $0.56 \pm 0.70$ & $0.26 \pm 0.51$ \\
\hline $\begin{array}{l}\text { Bend down to pickup } \\
\text { clothing from the floor }\end{array}$ & $1.79 \pm 1.19$ & $1.42 \pm 1.12$ & $1.09 \pm 0.97$ \\
\hline Turn taps on and off & $1.70 \pm 1.26$ & $1.37 \pm 1.04$ & $1.20 \pm 0.96$ \\
\hline Work in office/house & $1.73 \pm 1.03$ & $1.69 \pm 1.01$ & $1.19 \pm 0.91$ \\
\hline
\end{tabular}

rheumatoid Arthritis. In the study population most of the subjects are belongs to age $>45$ years, which indicates ageing is a major risk factor for the development of RA.

Smokers in this study were found to be $(46.87 \%)$ which indicates smoking is the major risk factor for the development of rheumatoid arthritis similar to past studies. One retrospective cohort study performed by the Onurozeturk et a $l^{20}$ shows the quality of life is much affected in smokers than non-smokers in rheumatoid arthritis with mean score of $42.64 \pm 13.3$ vs. $46.9 \pm 13.821$.

Initiation of this study we found that quality of life in the study population varies from one person to other based on their disease severity, progression and presence of co-morbidities. In this HRQoL study mostly affected domains are physical functioning, mental health and role emotional with a mean score of 28.98, 33.3 and 42.57. One cohort study conducted by Esam Mohammad abu al-fadl et $a l^{1}$ reported that rheumatoid arthritis patients have a greater impact on multiple domains of health related quality of life with mean scores of 62.12 , 52.56 and 44.01 .

This suggests that psycho -education (or) specific intervention by health care provider can increase the quality of life in Rheumatoid Arthritis patients. ${ }^{22}$

Most of the studies estimated quality of life in rheumatoid arthritis by using HAQ, SF-36 health survey and some pain scales and concluded that rheumatoid arthritis affects the quality of life. Fewer studies suggest that quality of life is much worse in rheumatoid arthritis compare to other musculoskeletal diseases such as ankylosing spondlyitis.

In this study we assessed the impact of clinical pharmacist mediated patient counseling on quality of life by providing patient information leaflet regarding disease, drug and lifestyle modification.

The HRQOL in the present study population in multiple domains at baseline and last follow up is physical functioning $28.98 \pm 16.35$ and $41.17 \pm 16.5$, role physical $28.98 \pm 16.35$ and $41.17 \pm 16.15$, body pains $47.35 \pm 12.80$ and $31.70 \pm 9.83$, general health $28.37 \pm 12.86$ and $41.85 \pm 12.59$, vitality $40.78 \pm 11.49$ and $54.4 \pm 11.02$, role emotional $33.3 \pm 19.2$ and $58.18 \pm 20.12$, social function $35.12 \pm 16.20$ and $58.17 \pm 14.31$, mental health $42.57 \pm 12.071$ and $62.141 \pm 13.412$ and overall score at p-value is 0.0001 is significant.

The health outcome measures such as ESR, CRP, and $\mathrm{RF}$ at the baseline and final follow up were found to be ESR 72.04 \pm 41.53 and $59.51 \pm 36.18$, CRP $59.51 \pm 36.18$ and $0.685 \pm 0.326$ and $\mathrm{RF} 31.97 \pm 37.01$ and $10.27 \pm 5.24$ which are similar to results of the study conducted by J.Hill et al. ${ }^{23}$

The results show that clinical pharmacist mediated patient counseling will have positive impact on quality of life in both physically as well as mentally.

\section{CONCLUSION}

Rheumatoid Arthritis is a chronic autoimmune disorder which limits patient activities in terms of physical function, social, and psychological status, and pharmacist plays an important role in management of rheumatoid arthritis by providing their patient centered pharmaceutical care services. The present study also demonstrated the positive influence on various domain of quality of life by providing the patient counseling through the patient information leaflet. In conclusion, the pharmacist based patient education and counseling have a 
greater positive impact on the quality of life in rheumatoid arthritis patients.

\section{ACKNOWLEDGEMENTS}

The authors would like to thank all medicos and allied healthcare staffs of RDT Hospital, Bathalapalli, Anantapuramu for their assistance in data collection and staffs of division of pharmacy practice, Raghavendra Institute of Pharmaceutical Education and Research RIPER for their constant support and guidance throughout the study.

\section{CONFLICT OF INTEREST}

The author declares no conflict of interest.

Funds and Grants: NIL

\section{ABBREVIATIONS}

ACR: American College of Rheumatology; RA: Rheumatoid Arthritis; NSAIDs:Non Steroidal Anti-inflammatory Drugs; DMARDs: Disease Modifying Anti Rheumatoid Drugs; HRQoL: Health Related Quality of Life; HAQ: Health Assessment Questionnaires; SF36: Short Form-36; ESR: Erythrocyte Sedimentation Rate; CRP: C Reactive Protein; IRB: Institutional Review Board; RF: Rheumatoid Factor; QoL: Quality of Life; BMI: Body Mass Index.

\section{REFERENCES}

1. Fries JF, et al. Measurement of patient outcome in arthritis. Arthritis Rheum. 1980;23(2):137-45.

2. Pincus $\mathrm{T}$, et al. Assessment of patient satisfaction in activities of daily living using a modified Stanford Health Assessment Questionnaire. Arthritis Rheum. 1983;26(11):1346-53.

3. Pincus $\mathrm{T}$, et al. Toward a multidimensional health assessment questionnaire (MDHAQ). Arthritis Rheum. 1999;42(10):2220-30.

4. Siegert $\mathrm{CE} \mathrm{H}$, et al. Measurement of disability in Dutch rheumatoid arthritis patients. Clin Rheumatol. 1984;3(3):305-9.

5. Kirwan JR, et al. Stanford Health Assessment Questionnaire modified to assess disability in British patients with rheumatoid arthritis. $\mathrm{Br} \mathrm{J}$ Rheumatol. 1986;25(2):206-9.
6. Ekdahl C, et al. Assessing disability in patients with rheumatoid arthritis. Use of a Swedish version of the Stanford Health Assessment Questionnaire. Scand J Rheumatol. 1988;17(4):263-71.

7. Guillemin F, et al. Measurement of the functional capacity in rheumatoid arthritis: A French adaptation of the Health Assessment Questionnaire (HAQ). Rev Rheum Mal Osteoartic. 1991;58(6):459-65

8. Shehab D, et al. Validation of the Arabic version of the health assessment questionnaire (HAQ) in patients with rheumatoid arthritis. Rev Rheum Eng Ed. 1998;65(6):387-92.

9. Brain RW. 2010. Inflammatory joint disease: in college. Davidson's principles and practice of medicine, (21 $1^{\text {st }}$ edition M. Doherty and S H. Ralston) pp. 10881092. Churchill Livingstone ELSEVIER.

10. Leon Shargel, 2007. ОTC agents for Pain, Cough, Cold and allergic rhinitis: in college. Comprehensive pharmacy Review, ( $6^{\text {th }}$ edition, Gerald E Schumacher and Jennifer D Smith) pp. 651-652. Lippincott Williams and Wilkins.

11. Richard A Helms, 2000. Rheumatoid arthritis: in college. Textbook of drug and disease management, ( $8^{\text {th }}$ edition, Eric G Boyee) pp. 1711-1724. Lippincott Williams and Wilkins.

12. Roger Walker., 2012. Rheumatoid arthritis and osteoarthritis: in college. Clinical pharmacy and therapeutics, (5th edition, D J Pang and G M Brough) pp. 832838. Churchill Living stone ELSEVIER.

13. Bedi GS, et al. Quality of life in Indian patients with rheumatoid arthritis. Qual Life Res. 2005;14(8):1953-8.

14. R S Satoskar., 2011. Pharmacotherapy of rheumatoid arthritis. Pharmacology and Pharmacotherapeutics. (22 ${ }^{\text {nd }}$ edition, Nirmala N Rege) pp. 1039-1041. Popular prakshan publications.

15. Michael MW, et al. Clinically important changes in short form 36 health survey scales for use in Rheumatoid arthritis in clinical trials the impact of low responsiveness. Arthritis Care and Research. 2014;(66):1783-9.

16. Talamo J, et al. Use of short form 36 for health status measurement in rheumatoid arthritis. British Journal of Resaerch. 1997;(36):463-9.

17. Lean $\mathrm{M}$, et al. Measures of functional status and quality of life in rheumatoid arthritis. Arthritis Care and Research. 2011;(63):S4-S13.

18. Chopra A, et al. Prevalence of rheumatic diseases in rural population in western India Journal of Associate Physician India. 2002;49:240-6.

19. American Thoracic Society. ATS Statement: guidelines for the six-minute walk test. Am J Respir Crit Care Med. 2002;166(1):111-17. Available from: www. atsjournals.org. [Cited 2013 Apr 10]

20. Onurozeturk, et al. The quality of life difference between smokers and non -smokers in Rheumatoid arthritis and ankylosing spondlyitis. Journal of Addiction Research Therapy. 2014;(05):2-6.

21. Esam Mohammad Abu, et al. Assessment of health related quality of life, Anxiety and depression in patients with early rheumatoid arthritis. The Egyptian Rheumatologist. 2014;(36):51-6.

22. Harrison TR, 2005. Rheumatoid arthritis: in college. Harrison's principles of medicine (16th edition Peter E Lipsky) pp. 1968-1975. Mc Graw Hill publications.

23. J Hill HB, et al. Effect of patient education on adherence to drug treatment for Rheumatoid arthritis. Annals of Rheumatic Disease. 